\title{
Article \\ A Real-World Application of Liquid Biopsy in Metastatic Colorectal Cancer: The Poseidon Study
}

\author{
Letizia Procaccio ${ }^{1,2,+} \mathbb{D}$, Francesca Bergamo ${ }^{1,+}{ }^{\text {, Francesca Daniel }}{ }^{1}$, Cosimo Rasola ${ }^{1,2}$, Giada Munari ${ }^{3,4}$, \\ Paola Biason ${ }^{1}$ (D), Stefania Crucitta ${ }^{5}$, Giulia Barsotti ${ }^{1,2}$, Giulia Zanella ${ }^{1}$, Valentina Angerilli ${ }^{3}$, Cristina Magro ${ }^{1}$, \\ Silvia Paccagnella ${ }^{3}$, Veronica Di Antonio ${ }^{1}$, Fotios Loupakis ${ }^{1}$, Romano Danesi ${ }^{5}$, Vittorina Zagonel ${ }^{1}$, \\ Marzia Del $\operatorname{Re}^{5}\left(\mathbb{D}\right.$, Sara Lonardi ${ }^{6, *}$ (D) and Matteo Fassan ${ }^{3,4}$
}

1 Oncology Unit 1, Department of Oncology, Veneto Institute of Oncology—IRCCS, 35128 Padova, Italy; letizia.procaccio@iov.veneto.it (L.P.); francesca.bergamo@iov.veneto.it (F.B.); francesca.daniel@iov.veneto.it (F.D.); cosimo.rasola@iov.veneto.it (C.R.); paola.biason@iov.veneto.it (P.B.); giulia.barsotti@iov.veneto.it (G.B.); giulia.zanella@iov.veneto.it (G.Z.); cristina.magro@iov.veneto.it (C.M.); veronica.diantonio@iov.veneto.it (V.D.A.); fotiosloupakis@gmail.com (F.L.); vittorina.zagonel@iov.veneto.it (V.Z.)

2 Department of Surgery, Oncology, and Gastroenterology, University of Padova, 35121 Padova, Italy

3 Surgical Pathology Unit, Department of Medicine (DIMED), University of Padova, 35121 Padova, Italy; giada.munari@gmail.com (G.M.); valentina.angerilli@gmail.com (V.A.); silviapak80@gmail.com (S.P.); matteo.fassan@gmail.com (M.F.)

4 Veneto Institute of Oncology (IOV-IRCCS), 35128 Padova, Italy

5 Clinical Pharmacology and Pharmacogenetics Unit, Department of Clinical and Experimental Medicine, University Hospital of Pisa, 56121 Pisa, Italy; stefania.crucitta@gmail.com (S.C.); romano.danesi@ao-pisa.toscana.it (R.D.); marzia.delre@gmail.com (M.D.R.)

updates

Citation: Procaccio, L.; Bergamo, F.; Daniel, F.; Rasola, C.; Munari, G.;

Biason, P.; Crucitta, S.; Barsotti, G.; Zanella, G.; Angerilli, V.; et al. A Real-World Application of Liquid Biopsy in Metastatic Colorectal Cancer: The Poseidon Study. Cancers 2021, 13, 5128. https://doi.org/ $10.3390 /$ cancers 13205128

Academic Editor: John Souglakos

Received: 8 September 2021

Accepted: 11 October 2021

Published: 13 October 2021

Publisher's Note: MDPI stays neutral with regard to jurisdictional claims in published maps and institutional affiliations.

Copyright: (C) 2021 by the authors Licensee MDPI, Basel, Switzerland. This article is an open access article distributed under the terms and conditions of the Creative Commons Attribution (CC BY) license (https:/ / creativecommons.org/licenses/by/ $4.0 /)$.
6 Oncology Unit 3, Department of Oncology, Veneto Institute of Oncology-IRCCS, 35128 Padova, Italy

* Correspondence: sara.lonardi@iov.veneto.it; Tel.: +39-0498215953

+ These authors contributed equally to this work.

Simple Summary: The choice of first-line regimen represents a critical step in the therapeutic road for patients with metastatic colorectal cancer (mCRC) because the response to first-line treatment is the primary determinant of outcomes. The extended characterization of RAS and BRAF mutational status is one the key points to select the optimal first-line therapy. Despite the great strides, there are still many challenges in the decision-making regarding the upfront strategy in mCRC patients. RAS testing turnaround time and the unavailability of tissue are the factors most frequently cited by physicians for treating $\mathrm{mCRC}$ patients with unknown $R A S$ status, particularly in small volume centers. An accurate blood-based $R A S / B R A F$ mutation assay with fast turnaround time would help circumvent these hurdles. Our experience suggests that genotyping $R A S / B R A F$ to guide therapy may be the first use of liquid biopsy in the daily care with mCRC patients, particularly in the urgent situation to define the first-line regimen.

Abstract: Background: First-line decision making is the key to the successful care of mCRC patients and $R A S / B R A F$ status is crucial to select the best targeted agent. In hub centers, a relevant proportion of patients referred from small volume centers may not have standard tissue-based (STB) molecular results available at the time of the first visit (T0). Liquid biopsy (LB) may help circumvent these hurdles. Methods: A monoinstitutional prospective head-to-head comparison of LB versus (vs.) STB testing was performed in a real-world setting. Selection criteria included: mCRC diagnosis with unknown RAS/BRAF status at T0, tumoral tissue archived in external centers, no previous treatment with anti-EGFR. At T0, patients underwent plasma sampling for LB testing and procedure for tissue recovery. $R A S / B R A F$ genotyping was carried out by droplet digital PCR on circulating-tumoral (ct) DNA. The primary endpoint was the comparison of time to LB (T1) vs. STB (T2) results using the Mann-Whitney U test. Secondary endpoints were the concordance between LB and STB defined as overall percent agreement and the accuracy of LB in terms of specificity, sensitivity, positive and negative predictive value. We also performed an exploratory analysis on urinary (u) ctDNA. Results: A total of 33 mCRC patients were included. Mean T1 and T2 was 7 and 22 days (d), respectively 
$(p<0.00001)$. T2 included a mean time for archival tissue recovery of $17 \mathrm{~d}$. The overall percent agreement between LB and STB analysis was $83 \%$. Compared to STB testing, LB specificity and sensitivity were $90 \%$ and $80 \%$, respectively, with a positive predictive value of $94 \%$ and negative one of $69 \%$. In detail, at STB and LB testing, RAS mutation was found in $45 \%$ and $42 \%$ of patients, respectively; $B R A F$ mutation in $15 \%$. LB results included one false positive and four false negative. False negative cases showed a significantly lower tumor burden at basal CT scan. Concordance between STB and uctDNA testing was $89 \%$. Conclusions: Faster turnaround time, high concordance and accuracy are three key points supporting the adoption of LB in routinary $\mathrm{mCRC}$ care, in particular when decision on first-line therapy is urgent and tissue recovery from external centers may require a long time. Results should be interpreted with caution in LB wild-type cases with low tumor burden.

Keywords: liquid biopsy; metastatic colorectal cancer; real-world; first-line therapy; concordance; accuracy; turnaround time

\section{Introduction}

A key point in the successful management of patients with metastatic colorectal cancer (mCRC) is first-line treatment decision making. According to major guidelines and experts' recommendations, therapeutic choice could be guided by a combination of clinical considerations (i.e., patient's age and performance status, comorbidities, expectations and preferences, primary tumor location, treatment toxicity profile, physician's experience) and tumor molecular characteristics (i.e., RAS and BRAF mutational status) [1]. New emerging molecular markers such as microsatellite instability (MSI) status or mismatch repair (MMR) proteins expression, HER2 amplification or NTRK rearrangements are progressively entering the list of genes with relevant clinical implications [2-6].

$R A S$ mutational status represents a criterion for selecting patients who would benefit from anti-EGFR therapy because these drugs are effective [7,8] and registered in $R A S$ wild-type patients only, by the US Food and Drug Administration (FDA) and European Medicines Agency (EMA). Despite similar data, BRAF V600E mutation has never been definitely established as negative predictive determinant to anti-EGFRs [9,10], but major guidelines recommend testing for adjusting therapeutic intensity based on its strong prognostic effect and association to peculiar clinical characteristics [11-13].

According to National Comprehensive Cancer Network (NCCN) and American Society of Clinical Oncology (ASCO) guidelines, the detection of RAS and BRAF mutations is routinely carried out in tumor tissue from either biopsies or resected specimens of the primary tumor or of a metastatic lesion [13].

Unlike other diseases, such as non-small-cell lung cancer (NSCLC), tumor tissue availability is not a major hurdle in the ordinary management of mCRC. As a matter of fact, around $50 \%$ of $\mathrm{mCRC}$ patients present with metachronous metastases and therefore a previously resected primary tumor should be available in surgical pathology archives. Even in cases with synchronous metastatic onset, colonoscopy and/or liver biopsy make the access to tumor material relatively easy.

It is well known that patients often access high volume referral centers for initial surgery or for second opinion at the time of first-line treatment decision making. This causes the common situation of the need for retrieving as soon as possible the archival samples stored elsewhere and timely execution of molecular tests to allow the hub centers to select the optimal first-line therapy in advanced stages. In order to face this or any other issue for which tumor tissue is not available (i.e., insufficient quantity or quality of archival samples), circulating tumoral (ct) DNA analysis has been proposed as possible alternative for rapid molecular testing [13-16].

Nevertheless, there are several open questions that need to be answered before adopting ctDNA testing in the daily management of mCRC patients [17-20]. Data on real advantages in terms of turnaround time and reliability of results are limited [21]. 
Based on the above reported observations, we designed the present prospective study with the primary objective of evaluating the turnaround time of plasma $R A S / B R A F$ analyses compared to that of standard tissue-based (STB) methods in a cohort of consecutive mCRC patients referred to our center, with no molecular data at the time of their clinical oncology assessment for treatment decision making. In our exploratory longitudinal cohort observational study, we focused only on patients with advanced disease referred to our center for a second opinion because we were certain to find a greater amount of ctDNA than what it was present in patients at early stage of CRC. Secondary objectives included the accuracy of plasma-based RAS/BRAF testing conducted by means of digital droplet PCR (ddPCR), and exploratory analysis on the role of a fully automated technology (i.e., $\mathrm{Idylla}^{\mathrm{TM}}$ ) [22] and on urine samples as alternative source of ctDNA (uctDNA) $[23,24]$.

\section{Materials and Methods}

\subsection{Study Design}

The key eligibility criteria were the following: histological diagnosis of colorectal adenocarcinoma, metastatic disease, no previous testing for $R A S$ and/or BRAF mutations, no previous treatment with anti-EGFR targeted monoclonal antibodies.

The primary objective was to describe the current practice regarding STB and liquid biopsy (LB)-based molecular testing for RAS and BRAF mutations as relevant markers for clinical decision making in $\mathrm{mCRC}$ patients. For this purpose, the primary endpoint was to determine the turnaround time of LB (T1) compared to that of STB analysis (T2) recording the following time intervals (expressed in days): between the plasma sampling and LB result (turnaround of LB analysis, TLBA), between the plasma-sample shipment to the referent analysis laboratory and LB result (turnaround of analysis laboratory, LAB-time), between the recovery request of tissue sample from the center where it was collected and the tissue RAS/BRAF testing result (turnaround of STB analysis, TSTBA), and between the tissue sample entry to the referent pathology unit and STB result (turnaround of STB analysis, PAT-time). Blood sampling and tissue RAS/BRAF mutational status testing were performed by the research nurses of Veneto Institute of Oncology and by pathology department of University of Padua, respectively. RAS/BRAF status in LB was tested at the Pharmacogenetic Laboratories of the University Hospital of Pisa.

Secondary endpoints were the following: concordance between STB and LB analysis, accuracy of LB in terms of sensitivity, specificity, negative and positive predictive values. Notably, to evaluate concordance of LB versus (vs.) tissue $R A S / B R A F$ testing results, positive percent agreement, negative percent agreement, and overall percent agreement were calculated. To estimate the LB accuracy, we evaluated the specificity, sensitivity, positive and negative predictive value compared to STB results considered as standard reference. Among secondary endpoints, we also included exploratory analyses either on plasma KRAS testing by the novel fully automated Idylla ${ }^{\mathrm{TM}}$ method and on uctDNA $[23,24]$ compared to the STB genotyping in terms of turnaround times, concordance and accuracy in a real-world setting of mCRC patients.

\subsection{Sampling and Molecular Testing}

A single peripheral blood sample from each patient was collected in a K2 EDTA Vacutainer tube. Plasma samples were prepared from collected blood within $4 \mathrm{~h}$ of phlebotomy with two subsequently centrifugation: the first one at $1600 \times g$ for $10 \mathrm{~min}$, then the isolated plasma was centrifuged at $3000 \times g$ for $10 \mathrm{~min}$ and stored at $-80^{\circ} \mathrm{C}$. All plasma samples were shipped in dry-ice to the Pharmacogenetic Laboratories at the University Hospital of Pisa, where RAS/BRAF mutation analysis was carried out on ctDNA by using a digital droplet PCR (ddPCR, Biorad, Hercules, CA, USA).

Among enrolled patients harboring mutations in KRAS exons 2, 3 or 4, we selected 4 consecutive subjects to prospectively assess the presence of these mutations in their plasma samples also by the Idylla ${ }^{\mathrm{TM}}$ platform technique [23]. 


\subsection{Plasma-Based RAS/BRAF Mutation Testing}

CtDNA was extracted from $3 \mathrm{~mL}$ of plasma samples using the QIAmp circulating nucleic acid kit (Qiagen, Valencia, CA, USA). The ddPCR ${ }^{\mathrm{TM}}$ Screening Multiplex Kit (BioRad, Hercules, CA, USA) were used to assess the mutational status of KRAS (codons 12 and 13), NRAS (codons 12,13 and Q16) and BRAF (codon V600) genes. We employed QX200 ddPCR system (Bio-Rad, Hercules, CA, USA) using specific ddPCR Supermix with no dUTTP for probes. DdPCR analysis is based on the co-amplification of mutant or wildtype alleles (FAM- and HEX-labeled probes, respectively) [25]. QX200 droplet generator and C1000 Touch Thermo Cycler (Bio-Rad, Berkeley, CA, USA) were used for the DNA amplification with the following protocol: $95^{\circ} \mathrm{C}$ for $10 \mathrm{~min}$ followed by 40 cycles of $94^{\circ} \mathrm{C}$ for $30 \mathrm{~s}$ and $55{ }^{\circ} \mathrm{C}$ for $1 \mathrm{~min}$, then $98^{\circ} \mathrm{C}$ for $10 \mathrm{~min}$. DdPCR allows for the enumeration of rare mutant variants in complex mixtures of DNA (wild type and mutant) based on an emulsion droplet technology and Poisson's distribution. Mutation specific amplification occurs in each individual droplet, and counting the positive droplets gives precise and absolute target quantification. The results, obtained using a QX200 ddPCR system (Bio-Rad, Valencia, CA, USA), are reported as copies per $\mathrm{ml}$ (copies $/ \mathrm{mL}$ ) of mutant DNA alleles.

Droplets were read in the QX200 droplet reader (Bio-Rad, Berkeley, CA, USA) and analyzed using the Quantasoft software version 1.0.596 (Bio-Rad, Berkeley, CA, USA).

The software calculated the value of MAF as the ratio of drops positive for the mutant allele to drops positive for the mutant allele plus drops positive for the wild-type allele (percentage of mutant KRAS alleles). The sensitivity allowed the detection of very low allele frequencies down to $<0.02 \%$.

\subsection{Tissue-Based RAS/BRAF Mutation Testing}

For each patient, five $10 \mu \mathrm{m}$ paraffin embedded sections were used to extract the DNA using the QIAmp FFPE tissue Kit (Qiagen) according to the manufacturer's instructions. Extracted DNA was quantified using to spectrophotometer. The Myriapod Colon status kit (Diatech Pharmacogenetics, Jesi, Italy) was used to evaluate the mutational status of KRAS (exons 2, 3 and 4), NRAS (exons 2, 3 and 4) and BRAF (exon 15). This analysis is based on MALDI-TOF Mass Spectrometry technology associated with the Single Base Extension. The panel consisted of 8 multiplexes for sample, for each reaction 5-50 ng of DNA was used and analyzed the RAS and BRAF gene. The analysis was performed according to manufacturer's instructions. The results were analyzed using the analysis software of instrument. The sensitivity allowed the detection of mutation was $2.5 \%$.

\subsection{Additional Exploratory Analyses}

Some samples were analyzed with Idylla ${ }^{\mathrm{TM}}$ platform, a fully automated molecular system (Biocartis, Mechelen, Belgium) [23]. This technology combines sample preparation with PCR thermocycling and fluorescence detection of target sequences.

We used an aliquot of the same samples analyzed by ddPCR. These were then processed and frozen at $-80^{\circ} \mathrm{C}$ until they were used for Idylla analysis. One microliter of plasma sample was directly dispensed into the disposable cartridge test and the experiment started. Within approximately $2.5 \mathrm{~h}$, with a hands-on time of less than $2 \mathrm{~min}$, Idylla ${ }^{\mathrm{TM}}$ returns a real-time and reliable genotyping in patients with $\mathrm{mCRC}$ [26].

The sensitivity cut-off for the DNA detection assay was set at the lower limit of $1 \%$ mutant alleles.

\section{6. uctDNA Analyses}

Urine samples taken for ddPCR analysis were subjected to pre-analytical processes, centrifuged to remove debris and contaminants. Urine sample containers were pre-filled with $10 \mathrm{~mL}$ EDTA $(0.5 \mathrm{M}, \mathrm{pH} 8.0)$ and approximately $30 \mathrm{~mL}$ of urine was collected for each patient. Subsequently, urine samples were transferred and preserved into cfree $(\mathrm{f})$ DNA-BCT ${ }^{\circledR}$ tubes (Streck, Omaha, NE, USA). In this study, such containers were used to 
ensure comparability between ctDNA extracted from plasma and urine samples, as the same ddPCR method was used for the analysis.

The cell fraction was removed by centrifugation $\left(20 \mathrm{~min}\right.$ at $2000 \times g$ at $\left.+4{ }^{\circ} \mathrm{C}\right)$ and the supernatant was carefully transferred into a $15 \mathrm{~mL}$ tube. A second centrifugation was performed at $16,000 \times \mathrm{g}$ at $+4{ }^{\circ} \mathrm{C}$ to remove any cellular residues; $4 \mathrm{~mL}$ of processed urine was recovered for DNA extraction. The ctDNA was extracted using the QIAamp ${ }^{\circledR} \operatorname{ccfDNA}$ Mini kit (Qiagen $\mathrm{GmbH}$, Hilden, Germany) according to the manufacturer's protocol. The isolated ctDNA was stored at $-20^{\circ} \mathrm{C}$ until analysis.

\subsection{Statistical Analyses}

Variables were described using mean and median when continuous, and percentage when categorical.

To compare turnaround time (T1) of LB vs. STB (T2)—our primary endpoint—we used the Mann-Whitney U test.

To evaluate the accuracy of plasma-based $R A S / B R A F$ testing we evaluated sensitivity, specificity, negative and positive predictive values. Sensitivity was defined as the ratio between true positive (TP) cases and the sum of TP and false negative (FN) cases, specificity as the ratio between true negative (TN) cases and the sum of TN and false positive (FP) cases. Negative predictive value was estimated as the ratio between TN cases and the sum of TN and FN, positive predictive value as the ratio between TP cases and the sum of TP and FP ones.

\section{Results}

\subsection{Patient Characteristics}

From September 2018 to March 2019, a total of 33 consecutive external patients with histologically confirmed mCRC were included: 21 males and 12 females having a mean age of 60 years (range: $39-91$ years).

Patient baseline characteristics, and number and location of metastasis are summarized in Tables 1 and 2.

Table 1. Major clinical features and baseline characteristics of primary tumors at time of LB on plasma.

\begin{tabular}{ccc}
\hline Characteristic & & Number (\%) \\
\hline \multirow{2}{*}{ Age (y.o.) } & mean & 60 \\
& range & $39-91$ \\
Sex & Male & $21(64 \%)$ \\
& Female & $12(36 \%)$ \\
CEA level $>5 \mathrm{ng} / \mathrm{mL}$ & Yes & $19(58 \%)$ \\
& No & $14(42 \%)$ \\
Primary tumor single lesion & Yes & $29(88 \%)$ \\
& No & $4(12 \%)$ \\
Primary tumor location & right & $11(33 \%)$ \\
& left & $16(49 \%)$ \\
Primary tumor resected & rectum & $6(18 \%)$ \\
& Yes & $24(73 \%)$ \\
Mucinous histology & No & $9(27 \%)$ \\
& Yes & $7(21 \%)$ \\
& No & $21(64 \%)$ \\
& NA & $5(15 \%)$ \\
\hline
\end{tabular}


Table 2. Major characteristics of metastatic disease at time of LB on plasma.

\begin{tabular}{ccc}
\hline Characteristic & & Number (\%) \\
\hline \multirow{2}{*}{ Number of metastatic sites } & single & $13(39 \%)$ \\
Liver metastasis & multiple & $20(61 \%)$ \\
& Yes & $22(67 \%)$ \\
Number of total metastatic lesions & No & $11(33 \%)$ \\
Total tumor volume $\left(\mathrm{cm}^{3}\right)$ & mean & 9.2 \\
& range & $1-25$ \\
Number of CT lines prior to LB & mean & 158 \\
& range & $0.9-248$ \\
Anti-angiogenics prior to LB & 0 & $24(73 \%)$ \\
& 1 & $4(12 \%)$ \\
& 2 & $4(12 \%)$ \\
& $>2$ & $1(3 \%)$ \\
& Yes & $9(27 \%)$ \\
\hline
\end{tabular}

Primary tumor was not resected prior to liquid biopsy in $9 / 33$ patients $(27 \%)$ and located in rectum, left and right side in 18\%, $49 \%$ and 33\% of cases, respectively.

Regarding the metastatic sites, liver was the most frequent site of metastasis $(22 / 67$, $67 \%)$, followed by lymph-nodes (17/33, 51.5\%).

Considering the previous treatments, a total of 24 patients $(73 \%)$ had newly diagnosed disease and were naive to treatment. With respect to treated patients, $15 \%(5 / 33)$ received at least two lines of prior chemotherapy.

All patients were referred to our hub center for a second opinion to evaluate the systemic treatment initiation after that STB RAS/BRAF testing was performed by our center as we usually do at the same time as the first oncological visit.

\subsection{RAS/BRAF Mutational Status Analysis from Tissue and Plasma}

\subsubsection{Turnaround Times between STB Analysis and Plasma LB}

The $\mathrm{T} 1$ mean was 7 days (d) with the same median value (range: $2-12 \mathrm{~d}$ ), whereas the LAB-time mean was $4 \mathrm{~d}$ with a median value of $5 \mathrm{~d}$ (range: $1-10 \mathrm{~d}$ ).

The T2 mean was $22 \mathrm{~d}$ with a median value of $17 \mathrm{~d}$ (range: 7-65 d), whereas the mean and median of PAT-time were $6 \mathrm{~d}$ (range: 1-18).

T1 resulted significantly shorter when compared to T2 using Mann-Whitney U test $(p<0.00001)$. The comparison of T1 vs. T2 results (primary endpoint) is shown in Figure 1.

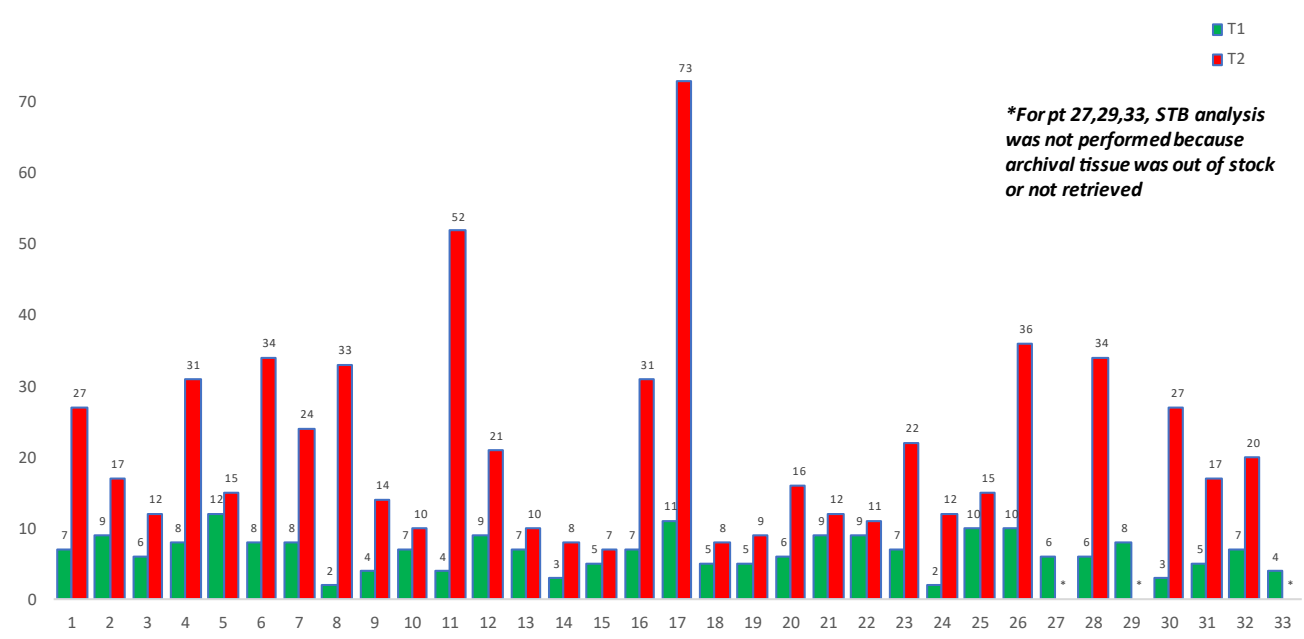

Figure 1. Comparison of time to LB (T1) vs. STB (T2) results. 


\subsubsection{Concordance between STB Analysis and Plasma LB}

Regarding the STB analysis, in 3 patients out of 33 RAS/BRAF genotyping was not carried out because one specimen was out of stock and two other ones resulted unretrieved at the data-lock point of the present study. Thus, we excluded these three patients from the STB analyses in terms of concordance with LB testing on plasma.

Among 30 patients, 15 (50\%) harbored RAS mutations in STB genotyping and $14(42 \%)$ in plasma-based analysis. V600E BRAF mutation was detected in STB and LB testing in five subjects. A total of $10(33 \%)$ tumoral tissue specimens resulted all wild type, whereas no $R A S / B R A F$ mutations were found in $14(42 \%)$ plasma samples (Table 3 ).

Table 3. Description of LB and STB results in terms of RAS/BRAF status.

\begin{tabular}{ccc}
\hline RAS/BRAF Status & LB & STB \\
\hline KRAS mutated & $13 / 33(39 \%)$ & $14 / 33(43 \%)$ \\
NRAS mutated & $1 / 33(3 \%)$ & $1 / 33(3 \%)$ \\
BRAF V600E mutated & $5 / 33(15 \%)$ & $5 / 33(15 \%)$ \\
All wild-type & $14 / 33(43 \%)$ & $10 / 33(30 \%)$ \\
NA & $0(0 \%)$ & $3 / 33(9 \%)$ \\
\hline
\end{tabular}

The RAS/BRAF mutational status determined by ddPCR from plasma corresponded to the data STB analysis in $25 / 30$ patients ( $83 \%$ overall percent agreement).

Considering tissue analysis as gold-standard for tumor genotyping, we calculated TP, FP, TN and FN results obtained from plasma-based LB. TP and FP cases were 16/30 and 1/30, respectively; FN were $4 / 30$ and TN were $9 / 30$. These data resulted in a $90 \%$ specificity and $94 \%$ PPV. Conversely, sensitivity and NPV were $80 \%$ and $69 \%$, respectively.

The concordance of RAS/BRAF status between LB and STB analysis from each patient (secondary endpoint) is summarized in Table 4.

Table 4. Accuracy of plasma-based LB vs. STB analysis.

\begin{tabular}{ccc}
\hline & RAS, BRAF Mutated on STB & All Wild-Type on STB \\
$(\boldsymbol{n})$ & False Positive (1) \\
\hline LB+ & True Positive (16) & True Negative (9) \\
\hline LB- & False Negative (4) & \\
\hline
\end{tabular}

3.2.3. Turnaround Times and Concordance between STB Analysis and Plasma KRAS Testing by Idylla ${ }^{\mathrm{TM}}$ Method

A total of four plasma samples from KRAS mutated patients based on STB analyses were tested by means of Idylla ${ }^{\mathrm{TM}}$ platform technique [23]. We were able to confirm the turnaround time of $120 \mathrm{~min}$ in all $(100 \%)$ analyzed samples. The Idylla ${ }^{\mathrm{TM}} \mathrm{ctDNA}$ assays confirmed STB results in three out four KRAS mutations (i.e., G13D, G12A and G12V). Interestingly, the only one case wild type at Idylla ${ }^{\mathrm{TM}}$ was reported to be wild type also at ddPCR.

\subsection{Description of False Results from RAS/BRAF Mutational Status Analysis by Plasma ddPCR}

False results subgroup $(\mathrm{N}=5)$ included one FP and four FN cases in comparison to the gold standard STB genotyping.

This subgroup was analyzed in depth taking into consideration major clinical features (i.e., age, CEA level) and baseline characteristics of primary tumor (i.e., single/multiple primary tumor, primary tumor location and resection, mucinous histology). We also investigated major characteristics of metastatic disease at time of LB and we reviewed the CT scan carried out closest to the blood extraction to calculate total tumor volume $\left(\mathrm{cm}^{3}\right)$, as a good surrogate of tumor burden. 
Overall, FN cases had lower total tumor volume $\left(8.5 \mathrm{~cm}^{3}\right.$ vs. $\left.52.6 \mathrm{~cm}^{3}\right)$ and lower number of total metastatic lesions (4.2 vs. 9.2) compared to those in true cases. All these data are summarized in Figure 2.

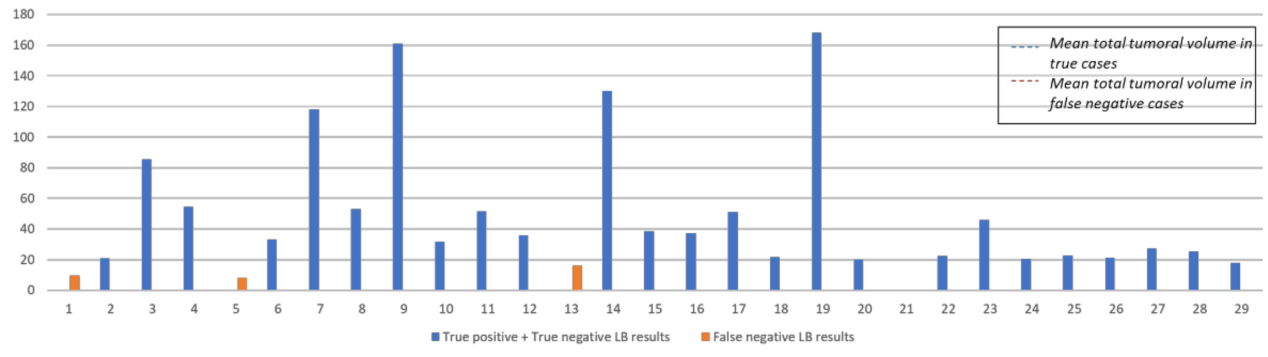

Figure 2. Comparison of false negative vs. true results of LB in terms of tumor volume.

The only FP case was patient number 20, in which LB identified a KRAS mutation with a MAF of 120 copies/mL, whereas it was identified as all wild type by tumoral STB genotyping.

\subsection{MAF Analysis}

For the 19 patients with detectable plasma RAS (14) or BRAF (5) mutations in LB analysis, the mean amount was 47.70 copies $/ \mathrm{mL}$ (range: $80-628000$ copies $/ \mathrm{mL}$ ). In particular, $R A S$ had a mean value of 58.38 copies/mL (range: $80-628000$ copies $/ \mathrm{mL}$ ) and BRAF had a mean value of 1400 copies/mL (range: 600-3000 copies/mL).

Given the possibility that the amount of circulating mutant alleles is related to the overall tumor burden or extent of metastatic invasion, the copies $/ \mathrm{mL}$ of mutant alleles in plasma were compared to the total tumor volume. We observed that the samples with the highest number of copies $/ \mathrm{mL}$ correlated to the largest total tumor volume.

\subsection{RAS/BRAF Mutational Status Analysis from Tissue and ucfDNA}

A total number of 19 consecutive mCRC patients with known KRAS mutation status were included. Baseline patients and primary tumor characteristics, metastatic disease features at the time of urine collection and previous treatments information are summarized in Table 5.

Table 5. Major characteristics of patients and primary and metastatic disease at time of LB on urine.

\begin{tabular}{ccc}
\hline Characteristic & & Patients (\%) \\
& & $n=19$ \\
Age mean (Y) & & $63(42-83)$ \\
CEA level $>5 \mathrm{ng} / \mathrm{mL}$ & single & $13(68)$ \\
Primary tumor single lesion & multiple & $1(5)$ \\
& right & $5(26)$ \\
Primary tumor location & left & $8(42)$ \\
& rectum & $6(32)$ \\
Primary tumor resected & Yes & $12(63)$ \\
& No & $7(37)$ \\
Mucinous histology & Yes & $4(21)$ \\
& No & $9(47)$ \\
Number of metastatic sites & NA & $6(32)$ \\
Site of metastasis & single & $9(47)$ \\
Number of total metastatic lesions (median) & multiple & $10(53)$ \\
Total tumor volume (cm3) (median) & Liver & $11(58)$ \\
& Non-liver & $8(42)$ \\
Number of CT lines prior to LB & & 15.2 \\
& & 190 \\
& 0 & $12(63)$
\end{tabular}


KRAS mutation was detected in 12 (63\%) STB analysis and in 10 (53\%) ucfDNA samples. All seven patients KRAS wild type on tumor biopsy were wild type also on urinary LB (Table 6).

Table 6. Accuracy of urine-based LB (uLB) vs. STB analysis.

\begin{tabular}{ccc}
\hline & $\begin{array}{c}\text { RAS, BRAF Mutated on STB } \\
(n)\end{array}$ & $\begin{array}{c}\text { All Wild-Type on STB } \\
(n)\end{array}$ \\
\hline $\mathbf{u L B}+$ & True Positive (10) & False Positive (0) \\
$\mathbf{u L B}-$ & False Negative (2) & True Negative (7) \\
\hline
\end{tabular}

Overall, concordance of KRAS mutational status between STB and urine-based LB testing was $89.5 \%(17 / 19$ cases $)$.

Accuracy of KRAS mutation detection on ucfDNA compared to STB is described in the following values: $83 \%$ of sensitivity, $100 \%$ specificity, with a positive predictive value and negative one of $100 \%$ and $78 \%$, respectively.

As well as for FN cases identified on plasma-based LB, we analyzed in depth the two FN results from urine-based LB taking into consideration clinical and pathological features. We observed that the first one underwent primary tumor resection before urine collection and had a mucinous histology; the second one presented with only extra-liver metastases (brain and lung); both were treatment-naive.

\section{Discussion}

The advent of the targeted therapy meant a step further in the direction to achieve the selection of the right therapy, to the right patients, at the right time. Concerning the management of mCRC patients, the accurate prescription of anti-EGFR agents is of high clinical importance. Thus, current guidelines recommend expanded $R A S$ analysis in order to identify patients for anti-EGFR therapy more precisely [15,27]. In particular, at initial diagnosis the timing of molecular testing results is relevant for first-line treatment. Despite the great steps forward [28-30], in two recent studies of mCRC patients evaluated for first-line therapy in the United States of America, approximately $30 \%$ of subjects failed to be tested on RAS mutational status [31,32]. In the real-world data reported by Sangaré et al. [32] and performed in 255 American public hospitals on a sample of over 17,000 patients, the RAS testing turnaround time was $>15$ days in $80 \%$ of study population [32]. These data are consistent with a European report [30] according to which the turnaround time of RAS testing can be extended beyond 10 days for external samples. These findings were confirmed by a survey of European physicians where the RAS testing turnaround time and the tissue unavailability resulted the most frequent factors cited for treating mCRC patients with unknown RAS status [33].

Moreover, external quality assessment surveys found that there is still great variability between country and country in the methods and times of RAS analysis, and that the latter expand especially in the cases of samples to be recovered [34,35]. All these factors contribute to hinder a wider realization of tailored therapy. An accurate blood-based $R A S / B R A F$ mutation assay with fast turnaround time would help circumvent these hurdles.

To our knowledge, the present analysis is one of the very few studies that shows in a daily clinical routine the usefulness of detecting $R A S / B R A F$ point mutations by ctDNA providing a head-to-head comparison in terms of turnaround time between liquid (i.e., plasma and urine) and solid testing.

The turnaround time of plasma analysis — the primary endpoint of our study — resulted faster compared to tumor-tissue analysis (STB). The STB tissue-based method had a mean and median turnaround time (T2) of $22 \mathrm{~d}$ and $17 \mathrm{~d}$, respectively, whereas the plasmabased (LB) method had both mean and median turnaround time of $7 \mathrm{~d}$ (i.e., T1). Notably, we calculated T2 as the interval between the tissue-based results and the request for specimen recovery. 
All tumor tissue samples were analyzed at the department of pathology of University of Padua but they were all external specimens, made and stored at various and distant centers. This is why the mean and the median T2 resulted superior to that observed in a previous study (mean $13 \mathrm{~d}$, median $11 \mathrm{~d}$ ) [35], which proposed a clinical validation of the RAS/BRAF mutations' detection from ctDNA in mCRC patients. In the mentioned analysis a large quote $(>90 \%)$ of tumor tissue genotyping was carried out in the clinical center where the FFPE specimens were made and stored [36].

In our clinical series, the main reason behind such a wide difference between the two turn-around times (T1 and T2) is the time needed to recover external tumoral tissue specimens. As matter of fact, the interval mean between the sample request and its receipt at our center was $17.2 \mathrm{~d}$ (median value was $12 \mathrm{~d}$, range 1-65 d), whereas the interval between the tissue-sample entry to our pathology unit and STB result (i.e., PAT-time) was $6 \mathrm{~d}$ only, as described above.

A necessary further step toward implementing blood- or urine-based $R A S / B R A F$ testing in the management of $\mathrm{mCRC}$ patients is to demonstrate concordance between ctDNA and tissue mutational status analysis, and to evaluate the accuracy of LB. Indeed, the secondary endpoints of our study were to analyze the concordance and the sensitivity, specificity and predictive values of ctDNA genotyping.

Our results showed a very high overall concordance, close to $90 \%$ ( $83 \%$ for plasmaand $89 \%$ for urine-based ddPCR), in comparison to the gold-standard tumor tissue analysis. These data are consistent with several retrospective and prospective reports [21,37-40], whereas in most of them liquid and solid biopsies were almost concomitant. Conversely, in our series the tumoral tissue sampling was concurrent with the blood or urine sampling in a very small cases only: over $85 \%$ of $R A S / B R A F$ genotyping was performed from tumoral tissue specimens collected at least one year before LB execution. For this reason, a similar value of concordance as emerged in the present study is even more noteworthy.

In our cohort, the plasma-based ddPCR analysis provided five false results (1 FP + $4 \mathrm{FN})$. Among them, a total of one and three patients did not harbor BRAF and KRAS mutation, respectively, that were detected in tissue samples.

Lack of RAS or BRAF mutations in plasma should be investigated because of the possible detrimental interaction of anti-EGFR agents in $R A S$ mutant patients. FN results may be attributed to emerging biological factors that affect ctDNA shed.

Commonly, the molecular landscape can be modified by chemotherapeutic and targeted agents in these tumors revealing an increasing number of acquired KRAS mutations that are notoriously correlated with secondary resistance to EGFR blockade [41,42]. However, the impact on the molecular profile derived from other therapies such as antiangiogenics or cytostatic agents deserves to be further investigated [43,44].

Recently, Tie et al. [45] observed changes in ctDNA shed for mCRC patients during the chemotherapy administration, with significant reduction in ctDNA values reported before cycle 2 in 41 of the 48 patients with concordant mutant samples in ctDNA and tissue. This could explain the lack of RAS mutation detection in patients recently exposed to chemotherapy, but it does not explain our four FN cases which were all chemo-naive.

Among the FN subgroup, the primary tumor was resected in two patients (i.e., patient number 2 and number 23), which presented metachronous lung metastasis at the time of LB. Primary tumor tissue genotyping resulted KRAS G12S and BRAF V600E mutated, respectively, whereas no $R A S$ neither $B R A F$ mutations were detected by cfDNA analysis. This discordance could only be partially attributed to the molecular heterogeneity between primary and metastatic lesions. An increasing number of studies considering inter-tumor heterogeneity (between primary tumors and metastases in the same patient) have demonstrated mutational discordance in $3.6-32.4 \%$ of cases [36,46,47].

Another and more likely explanation of this discordance is that detection of $R A S / B R A F$ mutation in ctDNA could be negatively affected by the low tumor load. An increasing number of analyses pointed out that the frequency of circulating mutant alleles is related to overall tumor burden or extent of metastatic invasion [48-50]. Indeed, when considering 
the copies/mL of the mutated subgroup, we observed a trend towards lower $R A S / B R A F$ plasma MAFs in patients with lower tumor burden (defined as total tumor volume). Overall, false cases had lower total tumor volume $\left(8.5 \mathrm{~cm}^{3}\right.$ vs. $\left.52.6 \mathrm{~cm}^{3}\right)$ and lower number of total metastatic lesions (4.2 vs. 9.2) compared to that in true cases.

In addition to the tumor burden, the site of metastasis (i.e., lung) could negatively impact copies $/ \mathrm{mL}$ in patient number 2 and number 23. A large number of analyses demonstrated that patients with liver involvement has higher MAFs compared with those without liver metastasis [39].

We could draw other interesting insights from analyzing copies $/ \mathrm{mL}$ due to the relatively large cohort size of patients with detectable $R A S$ or $B R A F$ mutations in our study ( $\mathrm{N}=19 / 30$ ). A widely large range (i.e., 80-628000 copy/mL) was showed, suggesting very high interindividual heterogeneity. This is consistent with the amount distribution reported in other studies [48-50]. As a matter of fact, a plethora of clinical and pathological characteristics could influence ctDNA shed such as the site of metastasis (peritoneum, lung), mucinous primary tumor histology and previous treatments. In the effort to better understand the biology of ctDNA as well as to explain plasma/tissue discrepancies in our cohort, we evaluated all these clinical and pathological features: data from plasma-based analysis suggested that tumor burden rather than intrinsic biological characteristics of tumor may impact ctDNA release. In contrast, our exploratory analysis on uctDNA would seem to strengthen the role of biological traits: out of the two FN results, the first one had a mucinous histology and the second one presented with only extra-liver metastases (brain and lung).

However, tumor heterogeneity and variable DNA shed fail to fully account for the recurring reports of inaccurate ctDNA genotyping reported in literature $[13,15,17,36,48,51,52]$. Similarly, the only FP case (patient number 20) of our clinical series could bring into play other issues. He was identified as all wild type on STB genotyping, whereas LB detected a $R A S$ mutation with a low MAF (120 copies/mL). At the time of blood sampling, he presented with sepsis and had undergone amputation of all toes due to a concomitant acute ischemia. We repeated plasma-based $R A S$ analysis after 2 weeks of antibiotic therapy and any $R A S$ mutation was no longer found.

Since a relevant percentage of cfDNA comes from peripheral blood cells (PBC) $[48,53,54]$, we supposed that somatic mutations within non-malignant hematopoietic cells, known clonal hematopoiesis [53,54], could explain this FP result. Recently, rare KRAS mutations detected in cfDNA were demonstrated derived from clonal hematopoiesis, not from tumor [54]. The clearest way to overcome this challenge could have been paired genotyping of both plasma cfDNA and PBC DNA. Unfortunately, PBC were discarded as usual when spinning plasma, so this analysis was not carried out.

Regarding our results of uctDNA analysis, the reported agreement, specificity and sensitivity $(89.5 \%, 100 \%$ and $83 \%$, respectively) are satisfactory considering the higher risk of contamination and degradation of urine sample and the absence of validated pre-analytic and analytic protocols. They are comparable to those reported in previous studies where the agreement fluctuates between $70 \%$ and $90 \%$, while the sensitivity is very variable and often suboptimal (63-93\%) also due to the inadequate volume of urine samples [55-60]. However, further studies on a larger number of patients are needed to confirm these promising results and explore the potential of uctDNA which could in some cases replace plasma biopsy due to its ease of execution and not requiring nursing procedures. To date, liquid urinary biopsy has been mainly investigated in lung and urinary tract tumors $[55,57,60]$.

\section{Conclusions}

Our results in terms of faster turnaround time, very high concordance and accuracy are three key points to implementing $R A S / B R A F$ blood-based analysis in the day-by-day care with $\mathrm{mCRC}$ patients, in particular in the urgent situation to define critical decision points for the anti-EGFRs administration. 
CtDNA in plasma represents a quick, feasible minimally invasive source of DNA alternative to tissue biopsy, that offer a real-time assessment of the cancer mutation status thanks to its repeatability during the patient's history. However, the analysis of ctDNA in plasma still needs an extensive clinical description, as confirmed by our data. In the present work, the plasma-based method exhibited $80 \%$ sensitivity and $69 \% \mathrm{NPV}$, in accordance with several previous studies $[13,36,51,52]$. As a matter of fact, the major technical challenges in testing ctDNA are the low fraction of the mutated allele, which is highly variable in different patients, and the broad dynamic range. Consequently, the most recent efforts are focusing on developing highly sensitive methodologies such as ddPCR and Idylla ${ }^{\mathrm{TM}}$ testing $[23,26,61,62]$

In our opinion, ddPCR is the most useful procedure in a daily clinical routine compared to Next Generation Sequencing and Idylla ${ }^{\mathrm{TM}}$, due to low costs and time-saving methodologies. Additionally, ddPCR allows a quantitative assessment of the fractional abundance of the mutation.

Despite the great value of the results presented, there are few limitations to our study. First of all, longitudinal blood extractions were not carried out in order to monitor dynamic mutational load, so our conclusions should be cautiously interpreted, in particular regarding correlation between MAFs distribution and specific clinical and pathological characteristics. Additionally, a progression free survival (PFS) analysis was not performed in order to evaluate potential impact in PFS of various MAF levels because survival data are still immature in our study $[50,63]$.

The undoubted advantages of genotyping with cfDNA are now recognized by international guidelines and regulatory agencies, in particular, the FDA approved the blood-based detection of EGFR mutations in NSCLC to identify eligible patients for tyrosine kinase inhibitors. Similarly, in the future, ctDNA may be used in the field of mCRC to help select $R A S$ wild-type patients suitable for anti-EGFR agents. There is a growing body of evidence to improve the broader development of ctDNA as a biomarker in several settings of CRC [64-71]. Indeed, increasing efforts of translational research are now directed in the long way to introduce the ctDNA analysis in carefully designed large prospective trials $[67,68,70]$.

Nevertheless, several challenges need to be overcome before this potential biomarker is introduced in our daily clinical practice with mCRC patients: First of all, pre-analytical issues such as the standardization of sample collection, processing and storage [72-74]. Moreover, there is still no consensus on the interpretation of results, in particular regarding the number of mutant droplets needed to interpret results as positive. There are many questions still answered. For example, should the cut-off of mutant droplets be lower in the early disease setting despite the resulting risk of too many false positives? Recent studies have tracked an increasing number of mutations in order to pick up relapse more reliably [75-77]. How much does it impact in terms of cost implications? Finally, could ctDNA also appear to be an independent prognostic biomarker in addition to its predictive capability, as recently suggested by El Massaoudi et al. [50]?

Despite these challenges, we shone a light on the first potential use of ctDNA in daily clinical practice to guide therapy in mCRC patients, in particular when decision on first-line therapy is urgent and tissue recovery from external centers may require a long time. Moreover, we expect that our increasing experience genotyping and interpreting ctDNA will allow to reach the international consensus that is still lacking and will address the other aforementioned open issues, finally introducing ctDNA in day-to-day clinical practice for many CRC management scenarios.

Author Contributions: Conceptualization, L.P., F.B., S.L., F.L.; methodology, M.F., L.P., F.B., S.L., F.L., G.M., P.B., M.D.R.; software, M.D.R., S.C.; validation, L.P., F.L., M.F., S.C., R.D.; formal analysis, L.P., F.B., S.L.; investigation, L.P.; resources, M.F., M.D.R., R.D., G.Z., C.M., V.D.A., V.A., S.P., G.M., C.R., G.B.; data curation, L.P., F.D., C.R., G.B.; writing-original draft preparation, L.P.; writing-review and editing, L.P., F.B., S.L., M.F., F.L., G.M., P.B., M.D.R., R.D., V.Z.; visualization, L.P.; supervision, F.B., S.L., V.Z.; project administration, L.P., F.B., S.L., V.Z.; funding acquisition, S.L., M.F. All authors 
have read and agreed to the published version of the manuscript. L.P. and F.B. contributed equally to this work as co-first author.

Funding: This research was partly supported by a grant from the Veneto Region and Italian Health Ministry's research program NET-2016-02363853 and RP-2014-00000395.

Institutional Review Board Statement: The study was conducted according to the guidelines of the Declaration of Helsinki and approved by the Institutional Ethics Committee of Veneto Institute of Oncology (Cod. Int. CE IOV Notifica 3 del 2015-Cod. Protocollo Oss_colon).

Informed Consent Statement: Informed consent was obtained from all subjects involved in the study.

Data Availability Statement: The data presented in our study are available on request from the corresponding author. The data are not publicly available due to our internal policy in terms of privacy restrictions.

Conflicts of Interest: The authors declare no conflict of interest.

\section{References}

1. Cremolini, C.; Schirripa, M.; Antoniotti, C.; Moretto, R.; Salvatore, L.; Masi, G.; Falcone, A.; Loupakis, F. First-line chemotherapy for mCRC—a review and evidence-based algorithm. Nat. Rev. Clin. Oncol. 2015, 12, 607-619. [CrossRef]

2. Battaglin, F.; Naseem, M.; Lenz, H.J.; Salem, M.E. Microsatellite instability in colorectal cancer: Overview of its clinical significance and novel perspectives. Clin. Adv. Hematol. Oncol. 2018, 16, 735.

3. Pietrantonio, F.; Di Nicolantonio, F.; Schrock, A.B.; Lee, J.; Tejpar, S.; Sartore-Bianchi, A.; Hechtman, J.; Christiansen, J.; Novara, L.; Tebbutt, N.; et al. ALK, ROS1, and NTRK Rearrangements in Metastatic Colorectal Cancer. J. Natl. Cancer Inst. 2017, 109. [CrossRef]

4. Siena, S.; Sartore-Bianchi, A.; Marsoni, S.; Hurwitz, H.; McCall, S.; Penault-Llorca, F.; Srock, S.; Bardelli, A.; Trusolino, L. Targeting the human epidermal growth factor receptor 2 (HER2) oncogene in colorectal cancer. Ann. Oncol. 2018, 29, 1108-1119. [CrossRef]

5. Taieb, J.; Jung, A.; Sartore-Bianchi, A.; Peeters, M.; Seligmann, J.; Zaanan, A.; Burdon, P.; Montagut, C.; Laurent-Puig, P. The Evolving Biomarker Landscape for Treatment Selection in Metastatic Colorectal Cancer. Drugs 2019, 79, 1375-1394. [CrossRef]

6. Antoniotti, C.; Ongaro, E.; Falcone, A.; Cremolini, C. The Winding Roadmap of Biomarkers toward Clinic: Lessons from Predictors of Resistance to Anti-EGFRs in Metastatic Colorectal Cancer. Int. J. Mol. Sci. 2018, 19, 2298. [CrossRef]

7. Douillard, J.-Y.; Oliner, K.S.; Siena, S.; Tabernero, J.; Burkes, R.; Barugel, M.; Humblet, Y.; Bodoky, G.; Cunningham, D.; Jassem, J.; et al. Panitumumab-FOLFOX4 Treatment and RAS Mutations in Colorectal Cancer. N. Engl. J. Med. 2013, 369, 1023-1034. [CrossRef]

8. Van Cutsem, E.; Lenz, H.-J.; Köhne, C.-H.; Heinemann, V.; Tejpar, S.; Melezínek, I.; Beier, F.; Stroh, C.; Rougier, P.; van Krieken, J.; et al. Fluorouracil, Leucovorin, and Irinotecan Plus Cetuximab Treatment and RAS Mutations in Colorectal Cancer. J. Clin. Oncol. 2015, 33, 692-700. [CrossRef] [PubMed]

9. Rowland, A.; Dias, M.M.; Wiese, M.; Kichenadasse, G.; McKinnon, R.; Karapetis, C.; Sorich, M. Meta-analysis of BRAF mutation as a predictive biomarker of benefit from anti-EGFR monoclonal antibody therapy for RAS wild-type metastatic colorectal cancer. Br. J. Cancer 2015, 112, 1888-1894. [CrossRef]

10. Pietrantonio, F.; Petrelli, F.; Coinu, A.; Di Bartolomeo, M.; Borgonovo, K.; Maggi, C.; Cabiddu, M.; Iacovelli, R.; Bossi, I.; Lonati, V.; et al. Predictive role of BRAF mutations in patients with advanced colorectal cancer receiving cetuximab and panitumumab: A meta-analysis. Eur. J. Cancer 2015, 51, 587-594. [CrossRef]

11. Seligmann, J.F.; Fisher, D.; Smith, C.G.; Richman, S.D.; Elliott, F.; Brown, S.; Adams, R.; Maughan, T.; Quirke, P.; Cheadle, J.; et al. Investigating the poor outcomes ofBRAF-mutant advanced colorectal cancer: Analysis from 2530 patients in randomised clinical trials. Ann. Oncol. 2017, 28, 562-568. [CrossRef]

12. Loupakis, F.; Moretto, R.; Aprile, G.; Muntoni, M.; Cremolini, C.; Iacono, D.; Casagrande, M.; Ferrari, L.; Salvatore, L.; Schirripa, M.; et al. Clinico-pathological nomogram for predicting BRAF mutational status of metastatic colorectal cancer. Br. J. Cancer 2015, 114, 30-36. [CrossRef]

13. Bettegowda, C.; Sausen, M.; Leary, R.J.; Kinde, I.; Wang, Y.; Agrawal, N.; Bartlett, B.R.; Wang, H.; Luber, B.; Alani, R.M.; et al. Detection of Circulating Tumor DNA in Early- and Late-Stage Human Malignancies. Sci. Transl. Med. 2014, 6, 224ra24. [CrossRef]

14. Sepulveda, A.R.; Hamilton, S.R.; Allegra, C.J.; Grody, W.; Cushman-Vokoun, A.M.; Funkhouser, W.K.; Kopetz, S.; Lieu, C.; Lindor, N.M.; Minsky, B.D.; et al. Molecular Biomarkers for the Evaluation of Colorectal Cancer: Guideline From the American Society for Clinical Pathology, College of American Pathologists, Association for Molecular Pathology, and the American Society of Clinical Oncology. J. Clin. Oncol. 2017, 35, 1453-1486. [CrossRef]

15. Dasari, A.; Morris, V.K.; Allegra, C.J.; Atreya, C.; Benson, A.B., 3rd; Boland, P.; Chung, K.; Copur, M.S.; Corcoran, R.B.; Deming, D.A.; et al. ctDNA applications and integration in colorectal cancer: An NCI Colon and Rectal-Anal Task Forces whitepaper. Nat. Rev. Clin. Oncol. 2020, 17, 757-770. [CrossRef]

16. Crowley, E.; Di Nicolantonio, F.; Loupakis, F.; Bardelli, A. Liquid biopsy: Monitoring cancer-genetics in the blood. Nat. Rev. Clin. Oncol. 2013, 10, 472-484. [CrossRef] 
17. Siravegna, G.; Mussolin, B.; Venesio, T.; Marsoni, S.; Seoane, J.; Dive, C.; Papadopoulos, N.; Kopetz, S.; Corcoran, R.; Siu, L.; et al. How liquid biopsies can change clinical practice in oncology. Ann. Oncol. 2019, 30, 1580-1590. [CrossRef]

18. Heidrich, I.; Ačkar, L.; Mohammadi, P.M.; Pantel, K. Liquid biopsies: Potential and challenges. Int. J. Cancer 2021, 148, 528-545. [CrossRef]

19. Burz, C.; Rosca, A.; Pop, V.-V.; Buiga, R.; Aldea, C.; Samasca, G.; Silaghi, C.; Sur, D.; Lupan, I.; Pricopie, A. Liquid biopsy challenge and hope in colorectal cancer. Expert Rev. Mol. Diagn. 2019, 19, 341-348. [CrossRef]

20. Vacante, M.; Ciuni, R.; Basile, F.; Biondi, A. The Liquid Biopsy in the Management of Colorectal Cancer: An Overview. Biomedicines 2020, 8, 308. [CrossRef]

21. García-Foncillas, J.; Tabernero, J.; Elez, E.; Aranda, E.; Benavides, M.; Camps, C.; Lewintre, E.J.; López, R.L.; Muinelo-Romay, L.; Montagut, C.; et al. Prospective multicenter real-world RAS mutation comparison between OncoBEAM-based liquid biopsy and tissue analysis in metastatic colorectal cancer. Br. J. Cancer 2018, 119, 1464-1470. [CrossRef]

22. Biocartis. Technical Sheet Idylla ctKRAS Mutation Test. 2017. Available online: https://media.biocartis.com/biocartis/ documents/TechSheet-ctKRAS-IVD-A4web.pdf (accessed on 11 October 2017).

23. Siravegna, G.; Marsoni, S.; Siena, S.; Bardelli, A. Integrating liquid biopsies into the management of cancer. Nat. Rev. Clin. Oncol. 2017, 14, 531-548. [CrossRef]

24. Botezatu, I.; Serdyuk, O.; Potapova, G.; Shelepov, V.; Alechina, R.; Molyaka, Y.; Anan'Ev, V.; Bazin, I.; Garin, A.; Narimanov, M.; et al. Genetic Analysis of DNA Excreted in Urine: A New Approach for Detecting Specific Genomic DNA Sequences from Cells Dying in an Organism. Clin. Chem. 2000, 46, 1078-1084. [CrossRef]

25. Olmedillas-López, S.; García-Arranz, M.; Olmo, D.G. Current and Emerging Applications of Droplet Digital PCR in Oncology. Mol. Diagn. Ther. 2017, 21, 493-510. [CrossRef]

26. Holm, M.; Andersson, E.; Osterlund, E.; Ovissi, A.; Soveri, L.-M.; Anttonen, A.-K.; Kytölä, S.; Aittomäki, K.; Osterlund, P.; Ristimäki, A. Detection of KRAS mutations in liquid biopsies from metastatic colorectal cancer patients using droplet digital PCR, Idylla, and next generation sequencing. PLoS ONE 2020, 15, e0239819. [CrossRef]

27. Van Cutsem, E.; Cervantes, A.; Adam, R.; Sobrero, A.; van Krieken, J.H.; Aderka, D.; Aguilar, E.A.; Bardelli, A.; Benson, A.; Bodoky, G.; et al. ESMO consensus guidelines for the management of patients with metastatic colorectal cancer. Ann. Oncol. 2016, 27, 1386-1422. [CrossRef]

28. Ciardiello, F.; Tejpar, S.; Normanno, N.; Mercadante, D.; Teague, T.; Wohlschlegel, B.; Van Cutsem, E. Uptake of KRAS mutation testing in patients with metastatic colorectal cancer in Europe, Latin America and Asia. Target. Oncol. 2011, 6, 133-145. [CrossRef] [PubMed]

29. Normanno, N.; Pinto, C.; Castiglione, F.; Bardelli, A.; Gambacorta, M.; Botti, G.; Nappi, O.; Siena, S.; Ciardiello, F.; Taddei, G.; et al. KRAS Mutations Testing in Colorectal Carcinoma Patients in Italy: From Guidelines to External Quality Assessment. PLoS ONE 2011, 6, e29146. [CrossRef] [PubMed]

30. Boleij, A.; Tack, V.; Taylor, A.; Kafatos, G.; Jenkins-Anderson, S.; Tembuyser, L.; Dequeker, E.; Van Krieken, J.H. RAS testing practices and RAS mutation prevalence among patients with metastatic colorectal cancer: Results from a Europe-wide survey of pathology centres. BMC Cancer 2016, 16, 825. [CrossRef] [PubMed]

31. Florea, A.; Garawin, T.; Sangaré, L.; Kelsh, M.A.; Lowe, K. An assessment of KRAS, NRAS, and BRAF testing prior to 1st line of therapy among mCRC patients treated at community cancer centers in the United States. J. Clin. Oncol. 2018, 36, 678. [CrossRef]

32. Sangaré, L.; Delli-Zotti, K.; Florea, A.; Rehn, M.; Benson, A.B.; Lowe, K.A. An evaluation of RAS testing among metastatic colorectal cancer patients in the USA. Future Oncol. 2021, 17, 1653-1663. [CrossRef]

33. Van Krieken, J.H.; Kafatos, G.; Bennett, J.; Mineur, L.; Tomášek, J.; Rouleau, E.; Fabian, P.; De Maglio, G.; García-Alfonso, P.; Aprile, G.; et al. Panitumumab use in metastatic colorectal cancer and patterns of RAS testing: Results from a Europe-wide physician survey and medical records review. BMC Cancer 2017, 17, 798. [CrossRef]

34. Lièvre, A.; Merlin, J.-L.; Sabourin, J.-C.; Artru, P.; Tong, S.; Libert, L.; Audhuy, F.; Gicquel, C.; Moureau-Zabotto, L.; Ossendza, R.-A.; et al. RAS mutation testing in patients with metastatic colorectal cancer in French clinical practice: A status report in 2014. Dig. Liver Dis. 2018, 50, 507-512. [CrossRef]

35. Tack, V.; Ligtenberg, M.J.; Tembuyser, L.; Normanno, N.; Borght, S.V.; Van Krieken, J.H.; Dequeker, E.M. External Quality Assessment Unravels Interlaboratory Differences in Quality of RAS Testing for Anti-EGFR Therapy in Colorectal Cancer. Oncologist 2015, 20, 257-262. [CrossRef]

36. Thierry, A.R.; Mouliere, F.; El Messaoudi, S.; Mollevi, C.; Lopez-Crapez, E.; Rolet, F.; Gillet, B.; Gongora, C.; Dechelotte, P.; Robert, B.; et al. Clinical validation of the detection of KRAS and BRAF mutations from circulating tumor DNA. Nat. Med. 2014, 20, 430-435. [CrossRef]

37. Grasselli, J.; Elez, E.; Caratù, G.; Matito, J.; Santos, C.; Macarulla, T.; Vidal, J.; Garcia, M.; Viéitez, J.; Paéz, D.; et al. Concordance of blood- and tumor-based detection of RAS mutations to guide anti-EGFR therapy in metastatic colorectal cancer. Ann. Oncol. 2017, 28, 1294-1301. [CrossRef]

38. Schmiegel, W.; Scott, R.J.; Dooley, S.; Lewis, W.; Meldrum, C.J.; Pockney, P.; Draganic, B.; Smith, S.; Hewitt, C.; Philimore, H.; et al. Blood-based detection ofRASmutations to guide anti-EGFR therapy in colorectal cancer patients: Concordance of results from circulating tumor DNA and tissue-basedRAStesting. Mol. Oncol. 2016, 11, 208-219. [CrossRef] 
39. Vidal, J.; Muinelo, L.; Dalmases, A.; Jones, F.; Edelstein, D.; Iglesias, M.; Orrillo, M.; Abalo, A.; Rodríguez, C.; Brozos, E.; et al. Plasma ctDNA RAS mutation analysis for the diagnosis and treatment monitoring of metastatic colorectal cancer patients. Ann. Oncol. 2017, 28, 1325-1332. [CrossRef]

40. Strickler, J.; Loree, J.; Ahronian, L.G.; Parikh, A.R.; Niedzwiecki, D.; Pereira, A.; McKinney, M.; Korn, W.M.; Atreya, C.E.; Banks, K.; et al. Genomic Landscape of Cell-Free DNA in Patients with Colorectal Cancer. Cancer Discov. 2018, 8, 164-173. [CrossRef]

41. Misale, S.; Yaeger, R.; Hobor, S.; Scala, E.; Janakiraman, M.; Liska, D.; Valtorta, E.; Schiavo, R.; Buscarino, M.; Siravegna, G.; et al. Emergence of KRAS mutations and acquired resistance to anti-EGFR therapy in colorectal cancer. Nature 2012, 486, 532-536. [CrossRef]

42. Misale, S.; Di Nicolantonio, F.; Sartore-Bianchi, A.; Siena, S.; Bardelli, A. Resistance to Anti-EGFR Therapy in Colorectal Cancer: From Heterogeneity to Convergent Evolution. Cancer Discov. 2014, 4, 1269-1280. [CrossRef] [PubMed]

43. Haibe, Y.; Kreidieh, M.; El Hajj, H.; Khalifeh, I.; Mukherji, D.; Temraz, S.; Shamseddine, A. Resistance Mechanisms to Antiangiogenic Therapies in Cancer. Front. Oncol. 2020, 10, 221. [CrossRef]

44. Itatani, Y.; Kawada, K.; Yamamoto, T.; Sakai, Y. Resistance to Anti-Angiogenic Therapy in Cancer-Alterations to Anti-VEGF Pathway. Int. J. Mol. Sci. 2018, 19, 1232. [CrossRef] [PubMed]

45. Tie, J.; Kinde, I.; Wang, Y.; Wong, H.L.; Roebert, J.; Christie, M.; Tacey, M.; Wong, R.; Singh, M.; Karapetis, C.; et al. Circulating tumor DNA as an early marker of therapeutic response in patients with metastatic colorectal cancer. Ann. Oncol. 2015, 26, 1715-1722. [CrossRef] [PubMed]

46. Knijn, N.; Mekenkamp, L.J.M.; Klomp, M.; Vink-Börger, M.E.; Van Tol, J.; Teerenstra, S.; Meijer, J.W.R.; Tebar, M.A.; Riemersma, S.; van Krieken, J.; et al. KRAS mutation analysis: A comparison between primary tumours and matched liver metastases in 305 colorectal cancer patients. Br. J. Cancer 2011, 104, 1020-1026. [CrossRef]

47. Kim, M.-J.; Lee, H.S.; Kim, J.H.; Kim, Y.J.; Kwon, J.H.; Lee, J.-O.; Bang, S.-M.; Park, K.U.; Kim, D.-W.; Kang, S.-B.; et al. Different metastatic pattern according to the KRAS mutational status and site-specific discordance of KRAS status in patients with colorectal cancer. BMC Cancer 2012, 12, 347. [CrossRef]

48. Thierry, A.R.; El Messaoudi, S.; Gahan, P.B.; Anker, P.; Stroun, M. Origins, structures, and functions of circulating DNA in oncology. Cancer Metastasis Rev. 2016, 35, 347-376. [CrossRef]

49. Mouliere, F.; El Messaoudi, S.; Gongora, C.; Guedj, A.-S.; Robert, B.; Del Rio, M.; Molina, F.; Lamy, P.-J.; Lopez-Crapez, E.; Mathonnet, M.; et al. Circulating Cell-Free DNA from Colorectal Cancer Patients May Reveal High KRAS or BRAF Mutation Load. Transl. Oncol. 2013, 6, 319-328. [CrossRef]

50. El Messaoudi, S.; Mouliere, F.; du Manoir, S.; Bascoul-Mollevi, C.; Gillet, B.; Nouaille, M.; Fiess, C.; Crapez, E.; Bibeau, F.; Theillet, C.; et al. Circulating DNA as a Strong Multimarker Prognostic Tool for Metastatic Colorectal Cancer Patient Management Care. Clin. Cancer Res. 2016, 22, 3067-3077. [CrossRef]

51. Normanno, N.; Cervantes, A.; Ciardiello, F.; De Luca, A.; Pinto, C. The liquid biopsy in the management of colorectal cancer patients: Current applications and future scenarios. Cancer Treat. Rev. 2018, 70, 1-8. [CrossRef]

52. Vitiello, P.P.; De Falco, V.; Giunta, E.F.; Ciardiello, F.; Cardone, C.; Vitale, P.; Zanaletti, N.; Borrelli, C.; Poliero, L.; Terminiello, M.; et al. Clinical Practice Use of Liquid Biopsy to Identify RAS/BRAF Mutations in Patients with Metastatic Colorectal Cancer (mCRC): A Single Institution Experience. Cancers 2019, 11, 1504. [CrossRef]

53. Genovese, G.; Kähler, A.K.; Handsaker, R.E.; Lindberg, J.; Rose, S.A.; Bakhoum, S.F.; Chambert, K.; Mick, E.; Neale, B.M.; Fromer, M.; et al. Clonal Hematopoiesis and Blood-Cancer Risk Inferred from Blood DNA Sequence. N. Engl. J. Med. 2014, 371, 2477-2487. [CrossRef]

54. Hu, E.; Ulrich, B.C.; Supplee, J.; Kuang, Y.; Lizotte, P.H.; Feeney, N.B.; Guibert, N.M.; Awad, M.M.; Wong, K.K.; Jänne, P.A.; et al. False-Positive Plasma Genotyping Due to Clonal Hematopoiesis. Clin. Cancer Res. 2018, 24, 4437-4443. [CrossRef] [PubMed]

55. Li, F.; Huang, J.; Ji, D.; Meng, Q.; Wang, C.; Chen, S.; Wang, X.; Zhu, Z.; Jiang, C.; Shi, Y.; et al. Utility of urinary circulating tumor DNA for EGFR mutation detection in different stages of non-small cell lung cancer patients. Clin. Transl. Oncol. 2017, 19, 1283-1291. [CrossRef]

56. Su, Y.-H.; Wang, M.; Brenner, D.E.; Norton, P.A.; Block, T.M. Detection of Mutated K-rasDNA in Urine, Plasma, and Serum of Patients with Colorectal Carcinoma or Adenomatous Polyps. Ann. N. Y. Acad. Sci. 2008, 1137, 197-206. [CrossRef] [PubMed]

57. Chen, S.; Zhao, J.; Cui, L.; Liu, Y. Urinary circulating DNA detection for dynamic tracking of EGFR mutations for NSCLC patients treated with EGFR-TKIs. Clin. Transl. Oncol. 2016, 19, 332-340. [CrossRef] [PubMed]

58. Fujii, T.; Barzi, A.; Sartore-Bianchi, A.; Cassingena, A.; Siravegna, G.; Karp, D.D.; Piha-Paul, S.; Subbiah, V.; Tsimberidou, A.M.; Huang, H.J.; et al. Mutation-Enrichment Next-Generation Sequencing for Quantitative Detection of KRAS Mutations in Urine Cell-Free DNA from Patients with Advanced Cancers. Clin. Cancer Res. 2017, 23, 3657-3666. [CrossRef] [PubMed]

59. Song, T.; Mao, F.; Shi, L.; Xu, X.; Wu, Z.; Zhou, J.; Xiao, M. Urinary measurement of circulating tumor DNA for treatment monitoring and prognosis of metastatic colorectal cancer patients. Clin. Chem. Lab. Med. 2018, 57, 268-275. [CrossRef]

60. Reckamp, K.L.; Melnikova, V.O.; Karlovich, C.; Sequist, L.V.; Camidge, D.R.; Wakelee, H.; Perol, M.; Oxnard, G.R.; Kosco, K.; Croucher, P.; et al. A Highly Sensitive and Quantitative Test Platform for Detection of NSCLC EGFR Mutations in Urine and Plasma. J. Thorac. Oncol. 2016, 11, 1690-1700. [CrossRef]

61. Vanova, B.; Kalman, M.; Jasek, K.; Kasubova, I.; Burjanivova, T.; Farkasova, A.; Kruzliak, P.; Busselberg, D.; Plank, L.; Lasabova, Z. Droplet digital PCR revealed high concordance between primary tumors and lymph node metastases in multiplex screening of KRAS mutations in colorectal cancer. Clin. Exp. Med. 2019, 19, 219-224. [CrossRef] 
62. Jacobs, B.; Claes, B.; Pomella, V.; Tejpar, S.; Bachet, J.-B.; Laurent-Puig, P.; Maertens, G.; Sablon, E. Abstract 940: Analytical and clinical validation of the Idylla ${ }^{\mathrm{TM}} \mathrm{ctKRAS}$ and ctNRAS-BRAF liquid biopsy tests identifies mCRC patient groups with high and low ctDNA shedding. Clin. Trials 2018, 78, 940. [CrossRef]

63. Elez, E.; Chianese, C.; Sanz-García, E.; Martinelli, E.; Noguerido, A.; Mancuso, F.; Caratù, G.; Matito, J.; Grasselli, J.; Cardone, C.; et al. Impact of circulating tumor DNA mutant allele fraction on prognosis in RAS -mutant metastatic colorectal cancer. Mol. Oncol. 2019, 13, 1827-1835. [CrossRef]

64. Tabernero, J.; Lenz, H.-J.; Siena, S.; Sobrero, A.; Falcone, A.; Ychou, M.; Humblet, Y.; Bouché, O.; Mineur, L.; Barone, C.; et al. Analysis of circulating DNA and protein biomarkers to predict the clinical activity of regorafenib and assess prognosis in patients with metastatic colorectal cancer: A retrospective, exploratory analysis of the CORRECT trial. Lancet Oncol. 2015, 16, 937-948. [CrossRef]

65. Wang, C.; Chevalier, D.; Saluja, J.; Sandhu, J.; Lau, C.; Fakih, M. Regorafenib and Nivolumab or Pembrolizumab Combination and Circulating Tumor DNA Response Assessment in Refractory Microsatellite Stable Colorectal Cancer. Oncologist 2020, 25, e1188-e1194. [CrossRef]

66. Parikh, A.; Corcoran, R. Monitoring resistance through liquid biopsy. Ann. Oncol. 2018, 29, 8-11. [CrossRef]

67. Siravegna, G.; Mussolin, B.; Buscarino, M.; Corti, G.; Cassingena, A.; Crisafulli, G.; Ponzetti, A.; Cremolini, C.; Amatu, A.; Lauricella, C.; et al. Clonal evolution and resistance to EGFR blockade in the blood of colorectal cancer patients. Nat. Med. 2015, 21, 795-801. [CrossRef]

68. Khan, K.H.; Cunningham, D.; Werner, B.; Vlachogiannis, G.; Spiteri, I.; Heide, T.; Fernández-Mateos, J.; Vatsiou, A.; Lampis, A.; Damavandi, M.D.; et al. Longitudinal Liquid Biopsy and Mathematical Modeling of Clonal Evolution Forecast Time to Treatment Failure in the PROSPECT-C Phase II Colorectal Cancer Clinical Trial. Cancer Discov. 2018, 8, 1270-1285. [CrossRef]

69. Sartore-Bianchi, A.; Loupakis, F.; Argilés, G.; Prager, M.G. Challenging chemoresistant metastatic colorectal cancer: Therapeutic strategies from the clinic and from the laboratory. Ann. Oncol. 2016, 27, 1456-1466. [CrossRef]

70. Tie, J.; Cohen, J.D.; Wang, Y.; Christie, M.; Simons, K.; Lee, M.; Wong, R.; Kosmider, S.; Ananda, S.; McKendrick, J.; et al. Circulating Tumor DNA Analyses as Markers of Recurrence Risk and Benefit of Adjuvant Therapy for Stage III Colon Cancer. JAMA Oncol. 2019, 5, 1710-1717. [CrossRef]

71. Tarazona, N.; Gimeno-Valiente, F.; Gambardella, V.; Zuniga, S.; Rentero-Garrido, P.; Huerta, M.; Roselló, S.; Martinez-Ciarpaglini, C.; Carbonell-Asins, J.; Carrasco, F.; et al. Targeted next-generation sequencing of circulating-tumor DNA for tracking minimal residual disease in localized colon cancer. Ann. Oncol. 2019, 30, 1804-1812. [CrossRef]

72. Meddeb, R.; Pisareva, E.; Thierry, A.R. Guidelines for the Preanalytical Conditions for Analyzing Circulating Cell-Free DNA. Clin. Chem. 2019, 65, 623-633. [CrossRef]

73. Haselmann, V.; Ahmad-Nejad, P.; Geilenkeuser, W.J.; Duda, A.; Gabor, M.; Eichner, R.; Patton, S.; Neumaier, M. Results of the first external quality assessment scheme (EQA) for isolation and analysis of circulating tumour DNA (ctDNA). Clin. Chem. Lab. Med. 2018, 56, 220-228. [CrossRef]

74. Pérez-Barrios, C.; Nieto-Alcolado, I.; Torrente, M.; Jiménez-Sánchez, C.; Calvo, V.; Gutierrez-Sanz, L.; Palka, M.; Donoso-Navarro, E.; Provencio, M.; Romero, A. Comparison of methods for circulating cell-free DNA isolation using blood from cancer patients: Impact on biomarker testing. Transl. Lung Cancer Res. 2016, 5, 665-672. [CrossRef]

75. Siena, S.; Bardelli, A.; Sartore-Bianchi, A.; Lonardi, S.; Leone, F.; Bergamo, F.; Tonini, G.; De Braud, F.; Pietrantonio, F.; Rimassa, L.; et al. Abstract A089: Exploiting clonal evolution and liquid biopsy to overcome resistance to anti-EGFR treatment in metastatic colorectal cancer: The CHRONOS trial. Clin. Trials 2018, 17, A089. [CrossRef]

76. Wang, B.; Wu, S.; Huang, F.; Shen, M.; Jiang, H.; Yu, Y.; Yu, Q.; Yang, Y.; Zhao, Y.; Zhou, Y.; et al. Analytical and clinical validation of a novel amplicon-based NGS assay for the evaluation of circulating tumor DNA in metastatic colorectal cancer patients. Clin. Chem. Lab. Med. 2019, 57, 1501-1510. [CrossRef]

77. Zhang, H.; Liu, R.; Yan, C.; Liu, L.; Tong, Z.; Jiang, W.; Yao, M.; Fang, W.; Chen, Z. Advantage of Next-Generation Sequencing in Dynamic Monitoring of Circulating Tumor DNA over Droplet Digital PCR in Cetuximab Treated Colorectal Cancer Patients. Transl. Oncol. 2019, 12, 426-431. [CrossRef] 